\title{
Pertumbuhan Bibit Tanaman Kelor (Moringa oleifera Lam.) Pada Beberapa Macam Media Organik dengan Teknik Pembibitan Tidak Langsung
}

\section{Growth of Drumstick Seedling (Moringa oleifera Lam.) on Various Organic Media Throughout Indirect Seedling Technique}

\author{
Rasmani $^{1}$, I Gusti Made Arya Parwata ${ }^{2}$, Bambang Budi Santoso ${ }^{2}$ \\ ${ }^{1)}$ Mahasiswa Program Pascasarjana, Program Studi Agronomi dan Hortikultura, Departemen \\ Agronomi dan Hortikultura, Fakultas Pertanian Institut Pertanian Bogor \\ ${ }^{2)}$ Kelompok Peneliti Pertanian Lahan Kering Fakultas Pertanian, Universitas Mataram \\ *corresponding author, email: rasmaniryeong@ gmail.com
}

Manuscript received: 02-09-2018. Accepted: 20-10-2018

\begin{abstract}
ABSTRAK
Penelitian eksperimental bertujuan mengetahui jenis media pembibitan organik yang baik bagi pertumbuhan bibit tanaman kelor (Moringa oleifera Lam.), telah dilaksanakan pada Januari-April 2017 di lahan nurseri pembibitan di Dasan Agung, Mataram. Perlakuan yang dipelajari pengaruhnya yaitu jenis media pembibitan organik meliputi media tanah, campuran tanah-serbuk gergaji, campuran tanah-cocopeat, campuran tanah-hancuran tongkol jagung, campuran tanah-seresah daun bambu. Rancangan percobaan diatur menggunakan Rancangan Acak Lengkap dengan 5 ulangan dengan masing-masing 5 serial unit percobaan. Hasil penelitian menunjukkan bahwa macam media pembibitan organik berpengaruh nyata terhadap pertumbuhan bibit kelor asal biji. Media campuran tanah-cocopeat, campuran tanahhancuran tongkol jagung, dan campuran tanah-seresah daun bambu merupakan media terbaik dan lebih cocok untuk pembibitan kelor dibandingkan dengan media tanah dan campuran tanah-serbuk gergaji.
\end{abstract}

Kata kunci : cocopeat, daun bambu, serbuk gergaji, tanah, tongkol jagung

\section{ABSTRACT}

The experimental research is aimed to find out the kind of nursery organic media for better growth of drumstick seedling. It was implemented in January-April 2017 in the nursery field in Dasan Agung, Mataram. The treatments studied were kinds of nursery media including soil media, mixture of soil-sawdust, mixture of soil-cocopeat, mixture of soil-crushed corncobs, mixture of soil-bamboo leaf litter. The experiment design was arranged in a Completely Randomized Design with 5 replications and each content of 5 serial experiment units. The result shows that the kind of seedling media significantly affected the growth to Moringa 
seedling growth. The soil-cocopeat mixture medium, soil-crushed corn cobs, and soilbamboo leaf litter were the best medium and more suitable for drumstick seedling compared to soil media and soil-sawdust mixture media.

Keywords: bamboo leaf, cocopeat, corn cobs, sawdust, soil

\section{PENDAHULUAN}

Tanaman kelor (Moringa oleifera Lam.) disebut dengan istilah "dinamit gizi" karena mengandung banyak nutrisi penting seperti zat besi, kalsium dan vitamin A. Kelor juga digunakan sebagai bahan utama ratusan jenis obat, baik untuk pencegahan maupun pengobatan. Berdasarkan fakta tersebut, maka tanaman kelor memiliki potensi untuk mengakhiri kekurangan gizi, kelaparan, serta mencegah dan menyembuhkan berbagai penyakit. Tanaman kelor juga memiliki peranan sangat penting untuk konservasi lahan kritis. Biji kelor dapat diolah menjadi serbuk biji kelor sebagai koagulan alami yang mampu menjernihkan air keruh (Krisnadi, 2015). Biji kelor dapat dimanfaatkan sebagai alternatif bahan bakar terbarukan untuk kegunaan di masa depan (Nawi, 2015).

Sehubungan dengan banyaknya manfaat dari tanaman kelor, maka pengembangan tanaman ini sangat perlu dilakukan. Untuk mendapatkan hasil tanaman kelor yang merupakan tanaman tahunan, penyediaan bibit berkualitas sangat diperlukan. Dikatakan oleh Santoso (2009) bahwa untuk mendapatkan pertanaman yang baik dari tanaman yang pada awalnya belum mendapatkan perhatian teknik budidaya, maka persiapan-persiapan teknik budidaya yang standar sangat diperlukan. Hal ini termasuk juga persiapan teknik pembibitan.

Salah satu cara memperoleh bibit tanaman yang berkualitas yaitu dengan perbanyakan tanaman melalui biji (secara generatif). Bibit tanaman kelor yang ditanam dari biji memiliki perakaran yang lebih dalam, membentuk akar tunggang yang lebar dan akar lateral yang tebal (Krisnadi, 2015). Pembibitan tanaman secara generatif dapat dilakukan secara langsung dan secara tidak langsung. Namun untuk mendapatkan bibit berkualitas, pembibitan tidak langsung melalui persemaian lebih baik dilakukan karena dapat menjamin keberhasilan penanaman di lapangan.

Pada sisi lain, pertumbuhan bibit sangat dipengaruhi oleh kondisi media pembibitannya. Kriteria media pembibitan yang baik yaitu memiliki bobot ringan, kepadatan (bulk density) rendah, drainase dan aerasi baik, kemampuan menahan air cukup baik, steril, bebas hama dan penyakit, mengandung nutrisi (unsur) yang cukup bagi pertumbuhan bibit atau memiliki kesuburan yang baik secara fisik, kimia, dan biologi (Pilot Proyek Restorasi/Rehabilitasi Lahan, 2013). Jenis media pembibitan yang umum digunakan yaitu media tanah yang mudah didapatkan. Akan tetapi, media tanah cenderung memadat akibat penyiraman, dan tidak semua tanah memiliki kesuburan fisik, kimia, dan biologi yang baik untuk pertumbuhan tanaman. Oleh karena itu, untuk mendapatkan media pembibitan yang baik dan subur, perlu dikombinasikan antara media tanah dengan media pembibitan lainnya, khususnya dengan media pembibitan berbahan dasar organik.

Media pembibitan berbahan dasar organik dapat berasal dari limbah-limbah pertanian seperti serbuk gergaji, cocopeat (serbuk sabut kelapa), limbah tongkol jagung, serta seresah daun bambu. Dalimoenthe (2013) menyebutkan bahwa penggunaan media sabut kelapa, sekam padi, serbuk gergaji, dan gambut yang diperkaya dengan pupuk kandang sapi 
memberikan hasil yang sama baiknya untuk persentase tanaman hidup, tinggi tanaman, diameter batang, serta jumlah daun bibit tanaman teh dibandingkan penggunaan media tanah.

Berdasarkan uraian tersebut di atas dan terbatasnya informasi tentang penggunaan media pembibitan tanaman kelor berbahan dasar organik berupa limbah pertanian, maka telah dilakukan penelitian yang bertujuan mengetahui jenis media pembibitan organik yang baik bagi pertumbuhan bibit tanaman kelor (Moringa oleifera Lam.),

\section{BAHAN DAN METODE}

\section{Tempat dan kondisi areal percobaan}

Percobaan dilaksanakan pada Januari-April 2017 di lahan pembibitan di Dasan Agung, Mataram, dengan ketinggian tempat 16 mdpl dan posisi geografis $8^{\circ} 34^{\prime} 47.19^{\prime \prime} S$ $116^{\circ} 05^{\prime} 47,91^{\prime}$ 'T. Rata-rata suhu udara di lokasi percobaan pada bulan Januari, Februari, Maret, dan April yaitu $27.4^{\circ} \mathrm{C}, 26.9^{\circ} \mathrm{C}, 27.6^{\circ} \mathrm{C}$, dan $27.5^{\circ} \mathrm{C}$ dengan rata-rata kelembaban udara $84 \%, 85 \%, 83 \%, 83 \%$. Curah hujan pada bulan Januari, Februari, Maret, dan April yaitu $152 \mathrm{~mm}, 235 \mathrm{~mm}, 159 \mathrm{~mm}$, dan $309 \mathrm{~mm}$ dengan rata-rata intensitas cahaya 327.9 $\mathrm{Cal} / \mathrm{cm}^{2}, 363.5 \mathrm{Cal} / \mathrm{cm}^{2}, 536.6 \mathrm{Cal} / \mathrm{cm}^{2}$, dan $543.5 \mathrm{Cal} / \mathrm{cm}^{2}$.

\section{Metode percobaan}

Perlakuan yang dipelajari pengaruhnya yaitu jenis media pembibitan yang meliputi media tanah, media campuran tanah-serbuk gergaji, media campuran tanah-cocopeat, media campuran tanah-hancuran tongkol jagung, dan media campuran tanah-seresah daun bambu. Pencampuran bahan-bahan media dengan perbandingan 1:1 (v/v). Setiap media perlakuan dibuat 5 ulangan dengan masing-masing terdiri atas 5 serial unit percobaan sehingga terdapat 125 unit percobaan. Percobaan dirancang menggunakan Rancangan Acak Lengkap.

\section{Pelaksanaan percobaan dan pemeliharaan bibit}

Media tanah diambil dari tanah kebun sedalam 20-25 cm (top soil) dan diayak. Bahan serbuk gergaji diambil dari tempat pemotongan kayu, sedangkan bahan cocopeat diambil dari tempat pembuatan sapu. Bahan tongkol jagung diambil dari tempat pengupasan jagung, dihancurkan hingga ukuran potongan $0.5-2.0 \mathrm{~cm}$. Daun bambu yang sudah hancur atau terpotong diambil dari lapisan terbawah tumpukan seresah daun bambu di bawah tegakan pepohonan bambu.

Media persemaian yang digunakan yaitu pasir dicampur sekam dengan perbandingan 1:1 (v/v). Biji kelor diambil dari tanaman yang tumbuh sehat dan telah berkadar air biji sekitar 15-20\%. Sebelum disemaikan biji direndam dalam air dan dibiarkan selama satu malam. Biji ditanam pada kedalaman 1-2 cm. Tiap lubang diisi satu biji dengan jarak $\pm 1 \mathrm{~cm}$. Semaian dipindah tanam ke polybag pembibitan saat semai berumur 7 hari setelah tabur biji. Penyiraman dilakukan dua hari sekali dan disesuaikan dengan kondisi media pembibitan. Penyiangan dilakukan dengan mencabut gulma yang tumbuh pada media pembibitan. Pada bibit tanaman yang mati atau tumbuh abnormal dilakukan penyulaman. Pemupukan dengan phonska dan dosis $5 \mathrm{~g} /$ polybag. Pengendalian hama menggunakan insektisida Curacron dengan konsentrasi 1cc/liter. Furadan ditaburkan di sekeliling bibit dengan dosis 3 gr/polybag. Pengendalian hama bekicot menggunakan garam kasar yang ditaburkan di sekitar 
polybag. Pengendalian penyakit menggunakan fungisida Dithane M-45 dengan konsentrasi $1.5 \mathrm{~g} / \mathrm{liter}$.

\section{Variabel dan analisis data}

Variabel respon pertumbuhan bibit diamati meliputi bobot berangkasan segar tajuk dan akar semai dilakukan pada semaian umur 7 HSS. Tajuk dan akar semaian dikeringkan dengan menggunakan oven hingga bobotnya konstan dan ditimbang untuk mendapatkan bobot berangkasan kering. Tinggi bibit diukur dari pangkal batang sampai ujung tertinggi. Diameter batang diukur menggunakan jangka sorong pada pangkal dan pada bagian tengah batang. Jumlah daun yang dihitung adalah jumlah daun yang sudah mekar sempurna. Pengukuran tinggi bibit, diameter batang, dan jumlah daun dilakukan 2 minggu sekali sejak pindah tanam hingga akhir percobaan. Pengukuran panjang akar primer dilakukan dilakukan dari pangkal akar hingga ujung akar menggunakan penggaris. Pengukuran panjang akar lateral menggunakan penggaris pada akar yang tumbuh dari akar primer dan dihitung juga jumlahnya. Pengukuran panjang akar primer, panjang akar lateral, dan jumlah akar lateral dilakukan pada semaian umur 7 HSS dan pengukuran berikutnya dilakukan 1 bulan sekali pada bibit yang telah pindah tanam.

Penimbangan bobot berangkasan segar tajuk dan akar bibit dilakukan setiap satu bulan sekali. Tajuk dan akar bibit dikeringkan menggunakan oven hingga beratnya konstan. Rasio tajuk-akar dihitung dengan membandingkan berat berangkasan kering tajuk dan akar bibit. Pada akhir percobaan dilakukan analisis media tanam di Laboratorium untuk mengetahui sifat fisik dan kimia pada masing-masing media pembibitan yang digunakan. Analisis data menggunakan Anova 5\% dan uji lanjut Beda Nyata Jujur pada taraf 5\% menggunakan program Minitab16.

\section{HASIL DAN PEMBAHASAN}

\section{Hasil penelitian}

Secara umum dapat dikatakan bahwa terdapat pengaruh nyata macam media pembibitan terhadap pertumbuhan bibit kelor selama 3 bulan periode pertumbuhan bibit. Biji yang digunakan sebagai bahan perbanyakan dalam penelitian ini berasal dari satu tanaman yang tumbuh subur di kawasan Kabupaten Lombok Utara (Dusun Panggung, Akar-Akar), bukan merupakan tanaman sumber benih, namun dapat dikatakan berkualitas baik. Hal ini terkait dengan tingkat keseragaman yang cukup tinggi (keragaman rendah) dari semai yang dihasilkan. Hasil pengukuran komponen pertumbuhan semai kelor umur 7 hari setelah tabur biji menunjukkan nilai standar deviasi yang rendah pada panjang akar primer (0.43), panjang akar lateral (0.08), jumlah akar lateral (1.50), bobot segar tajuk (0.01), bobot kering tajuk (0.01), bobot segar akar (0.01), dan bobot kering akar (0.01). Jadi, semai yang dipindah tanam ke polybag pembibitan adalah seragam (homogen). Adanya perbedaan pertumbuhan bibit selanjutnya adalah karena adanya pengaruh dari media yang digunakan.

Pertumbuhan bibit dipengaruhi oleh faktor kesuburan media pembibitannya. Media tanam yang subur memiliki sifat fisik dan sifat kimia yang baik. Tabel 1. dan Tabel 2. menunjukkan sifat fisik dan sifat kimia macam media pembibitan yang digunakan. Sedangkan Tabel 3. menunjukkan bahwa macam media pembibitan tidak berpengaruh nyata terhadap tinggi bibit saat umur 14 HSPT, 70 HSPT, dan 84 HSPT dan berpengaruh nyata saat 
bibit umur 28 HSPT, 42 HSPT, dan 56 HSPT. Penampilan akhir bibit merupakan manifestasi pertumbuhan dan perkembangannya selama kurun waktu tertentu. Pada penelitian ini, manifestasi pertumbuhan bibit dapat dilihat saat bibit berumur 3 bulan.

Tabel 1. Komponen fisik macam media pada periode akhir pembibitan

\begin{tabular}{lcc}
\hline \multicolumn{1}{c}{ Media Pembibitan } & $\begin{array}{c}\text { Kadar air } \\
(\%)\end{array}$ & $\begin{array}{c}\text { Bobot jenis } \\
(\mathrm{g} / \mathrm{ml})\end{array}$ \\
\hline Tanah $(\mathrm{T})$ & 20.57 & 2.07 \\
T + Serbuk gergaji & 22.67 & 1.91 \\
T + Cocopeat & 27.09 & 1.66 \\
T + Tongkol jagung & 16.10 & 2.00 \\
T + Daun bambu & 18.31 & 2.03 \\
\hline Keterangan: Data diperoleh dari hasil analisis media & pembibitan di Laboratorium Balai \\
Pengkajian Teknologi Pertanian NTB.
\end{tabular}

Tabel 2. Komponen kimia macam media pada periode akhir pembibitan

\begin{tabular}{lccccccc}
\hline Media Pembibitan & $\mathrm{pH}$ & $\begin{array}{c}\mathrm{C}- \\
\text { Organik } \\
(\%)\end{array}$ & $\begin{array}{c}\mathrm{KTK} \\
\mathrm{cmol} / \mathrm{kg}\end{array}$ & $\begin{array}{c}\mathrm{N}-\text { Total } \\
(\%)\end{array}$ & $\begin{array}{c}\text { P- } \\
\text { Tersedia } \\
(\mathrm{ppm})\end{array}$ & $\begin{array}{c}\mathrm{K}- \\
\text { Tersedia } \\
(\mathrm{ppm})\end{array}$ & $\mathrm{C} / \mathrm{N}$ \\
\hline Tanah (T) & 5.60 & 0.29 & 12.56 & 0.16 & 5.5 & 48.32 & 1.81 \\
& $(\mathrm{AM})$ & $(\mathrm{SR})$ & $(\mathrm{R})$ & $(\mathrm{R})$ & $(\mathrm{S})$ & $(\mathrm{ST})$ & $(\mathrm{SR})$ \\
T + Serbuk gergaji & 6.23 & 1.59 & 12.95 & 0.17 & 13.86 & 52.64 & 9.35 \\
& $(\mathrm{AM})$ & $(\mathrm{R})$ & $(\mathrm{R})$ & $(\mathrm{R})$ & $(\mathrm{ST})$ & $(\mathrm{ST})$ & $(\mathrm{R})$ \\
$\mathrm{T}+$ Cocopeat & 5.84 & 0.73 & 13.96 & 0.16 & 9.03 & 52.12 & 4.56 \\
& $(\mathrm{AM})$ & $(\mathrm{SR})$ & $(\mathrm{R})$ & $(\mathrm{R})$ & $(\mathrm{T})$ & $(\mathrm{ST})$ & $(\mathrm{SR})$ \\
T + Tongkol jagung & 5.88 & 0.98 & 14.36 & 0.20 & 8.54 & 56.86 & 4.90 \\
& $(\mathrm{AM})$ & $(\mathrm{SR})$ & $(\mathrm{R})$ & $(\mathrm{R})$ & $(\mathrm{T})$ & $(\mathrm{ST})$ & $(\mathrm{SR})$ \\
T + Daun bambu & 5.90 & 1.45 & 17.34 & 0.14 & 8.75 & 51.48 & 10.36 \\
& $(\mathrm{AM})$ & $(\mathrm{R})$ & $(\mathrm{S})$ & $(\mathrm{R})$ & $(\mathrm{T})$ & $(\mathrm{ST})$ & $(\mathrm{R})$ \\
\hline
\end{tabular}

Keterangan: Data diperoleh dari hasil analisis media pembibitan di Laboratorium Tanah, Tanaman, Pupuk, Air, Balai Pengkajian Teknologi Pertanian NTB. Kriteria sifat kimia menurut Balai Penelitian Tanah (2005). $\mathrm{AM}=$ agak masam. $\mathrm{SR}=$ sangat rendah. $\mathrm{R}=$ rendah. $\mathrm{S}=$ Sedang. $\mathrm{T}=$ Tinggi. $\mathrm{ST}=$ Sangat tinggi

Tabel 3. Tinggi bibit pada berbagai media pembibitan

\begin{tabular}{lcccccc}
\hline \multirow{2}{*}{ Media Pembibitan } & \multicolumn{7}{c}{ Tinggi bibit $(\mathrm{cm})$} \\
\cline { 2 - 7 } & HSPT & HSPT & HSPT & HSPT & HSPT & HSPT \\
\hline Tanah (T) & 13.90 & $20.16 \mathrm{~b}$ & $30.98 \mathrm{bc}$ & $53.26 \mathrm{ab}$ & 64.12 & 76.30 \\
T + Serbuk gergaji & 14.96 & $18.66 \mathrm{~b}$ & $27.20 \mathrm{c}$ & $46.17 \mathrm{~b}$ & 56.97 & 65.67 \\
T + Cocopeat & 15.01 & $20.95 \mathrm{~b}$ & $36.06 \mathrm{a}$ & $57.86 \mathrm{a}$ & 69.21 & 78.01 \\
T + Tongkol jagung & 14.36 & $20.44 \mathrm{~b}$ & $36.13 \mathrm{a}$ & $54.04 \mathrm{a}$ & 64.69 & 76.21 \\
T + Daun bambu & 15.72 & $24.40 \mathrm{a}$ & $34.09 \mathrm{ab}$ & $54.13 \mathrm{a}$ & 64.73 & 74.45 \\
\hline BNJ 5\% & tn & 2.50 & 4.51 & 7.28 & tn & tn \\
\hline
\end{tabular}

Keterangan: Angka yang diikuti dengan huruf yang sama pada kolom yang sama menunjukkan berbeda tidak nyata menurut uji BNJ pada taraf nyata 5\%. HSPT $=$ hari setelah pindah tanam. $\mathrm{tn}=$ tidak nyata 
Pada Tabel 4. tampak bahwa macam media pembibitan berpengaruh nyata selama 3 bulan periode pertumbuhan bibit terhadap diameter batang. Saat bibit umur 84 HSPT (menjelang waktu pindah tanam ke lapangan) bibit pada media tanah, tanah-cocopeat memiliki diameter batang yang berbeda tidak nyata dengan diameter batang bibit pada media lainnya, kecuali dengan bibit pada media tanah-serbuk gergaji.

Tabel 4. Diameter batang bibit pada berbagai media pembibitan

\begin{tabular}{lcccccc}
\hline \multirow{2}{*}{ Media Pembibitan } & \multicolumn{7}{c}{ Diameter batang $(\mathrm{cm})$} \\
\cline { 2 - 7 } & HSPT & HSPT & HSPT & HSPT & HSPT & HSPT \\
\hline Tanah (T) & $0.16 \mathrm{~b}$ & $0.24 \mathrm{~b}$ & $0.36 \mathrm{~b}$ & $0.49 \mathrm{~b}$ & $0.56 \mathrm{ab}$ & $0.63 \mathrm{ab}$ \\
T + Serbuk gergaji & $0.16 \mathrm{~b}$ & $0.20 \mathrm{c}$ & $0.30 \mathrm{c}$ & $0.43 \mathrm{c}$ & $0.51 \mathrm{~b}$ & $0.55 \mathrm{~b}$ \\
T + Cocopeat & $0.16 \mathrm{~b}$ & $0.26 \mathrm{~b}$ & $0.42 \mathrm{a}$ & $0.56 \mathrm{a}$ & $0.63 \mathrm{a}$ & $0.67 \mathrm{a}$ \\
T + Tongkol jagung & $0.16 \mathrm{~b}$ & $0.24 \mathrm{~b}$ & $0.41 \mathrm{ab}$ & $0.51 \mathrm{ab}$ & $0.59 \mathrm{a}$ & $0.63 \mathrm{a}$ \\
T + Daun bambu & $0.18 \mathrm{a}$ & $0.34 \mathrm{a}$ & $0.42 \mathrm{a}$ & $0.53 \mathrm{ab}$ & $0.60 \mathrm{a}$ & $0.65 \mathrm{a}$ \\
\hline BNJ 5\% & 0.014 & 0.024 & 0.05 & 0.06 & 0.08 & 0.09 \\
\hline
\end{tabular}

Keterangan: Angka yang diikuti dengan huruf yang sama pada kolom yang sama menunjukkan berbeda tidak nyata menurut uji BNJ pada taraf nyata $5 \% . \mathrm{HSPT}=$ hari setelah pindah tanam.

Tabel 5. memaparkan bahwa pengaruh macam media berfluktuasi selama periode pembibitan 3 bulan. Macam media pembibitan berpengaruh nyata terhadap jumlah daun bibit, kecuali pada bibit umur 14 HSPT, 70 HSPT, dan 84 HSPT. Macam media pembibitan tampak berpengaruh nyata pada saat bibit kelor berumur 28 HSPT, 42 HSPT, dan 56 HSPT.

Tabel 5. Jumlah daun bibit pada berbagai media pembibitan

\begin{tabular}{lcccccc}
\hline \multirow{2}{*}{ Media Pembibitan } & \multicolumn{7}{c}{ Jumlah daun (helai) } \\
\cline { 2 - 7 } & 14 HSPT & HSPT & HSPT & HSPT & HSPT & HSPT \\
\hline Tanah (T) & 5.48 & $8.92 \mathrm{ab}$ & $11.70 \mathrm{abc}$ & $13.35 \mathrm{a}$ & 10.87 & 11.13 \\
T + Serbuk gergaji & 5.60 & $7.60 \mathrm{~b}$ & $9.65 \mathrm{c}$ & $11.50 \mathrm{ab}$ & 10.27 & 10.67 \\
T + Cocopeat & 5.68 & $8.76 \mathrm{ab}$ & $12.65 \mathrm{a}$ & $12.85 \mathrm{a}$ & 9.00 & 11.13 \\
T + Tongkol jagung & 5.56 & $8.24 \mathrm{~b}$ & $12.20 \mathrm{ab}$ & $11.60 \mathrm{ab}$ & 10.00 & 10.47 \\
T + Daun bambu & 5.56 & $10.08 \mathrm{a}$ & $10.10 \mathrm{bc}$ & $10.40 \mathrm{~b}$ & 10.60 & 11.33 \\
\hline BNJ 5\% & tn & 1.61 & 2.17 & 2.10 & tn & tn \\
\hline
\end{tabular}

Keterangan: Angka yang diikuti dengan huruf yang sama pada kolom yang sama menunjukkan berbeda tidak nyata menurut uji BNJ pada taraf nyata 5\%. HSPT $=$ hari setelah pindah tanam. $\mathrm{tn}=$ tidak nyata.

Pertumbuhan tajuk yang baik ditentukan oleh akar yang bertanggung jawab menyerap air dan unsur hara dari media pembibitan atau media tumbuh. Macam media pembibitan yang digunakan dalam penelitian ini berpengaruh tidak nyata terhadap panjang akar primer dan panjang akar lateral bibit selama periode pertumbuhan 3 bulan (Tabel 6). Macam media pembibitan juga tampak berpengaruh nyata terhadap jumlah akar lateral saat bibit berumur 30 HSPT (Tabel 7). 
Tabel 6. Panjang akar primer dan akar lateral bibit pada berbagai media pembibitan

\begin{tabular}{lcccccc}
\hline \multirow{2}{*}{ Media Pembibitan } & \multicolumn{3}{c}{ Panjang akar primer $(\mathrm{cm})$} & \multicolumn{3}{c}{ Panjang akar lateral $(\mathrm{cm})$} \\
\cline { 2 - 7 } & 30 & 60 & 90 & 30 & 60 & 90 \\
& HSPT & HSPT & HSPT & HSPT & HSPT & HSPT \\
\hline Tanah (T) & 14.60 & 13.62 & 13.42 & 4.83 & 5.29 & 4.56 \\
T + Serbuk gergaji & 14.80 & 14.14 & 13.62 & 5.84 & 5.82 & 5.43 \\
T + Cocopeat & 14.22 & 15.18 & 17.90 & 5.01 & 5.00 & 4.49 \\
T + Tongkol jagung & 10.70 & 15.34 & 15.68 & 3.96 & 5.30 & 5.27 \\
T + Daun bambu & 12.50 & 17.62 & 15.04 & 5.74 & 4.84 & 4.71 \\
\hline BNJ 5\% & tn & tn & tn & tn & tn & tn
\end{tabular}

Keterangan $:$ HSPT $=$ hari setelah pindah tanam. $\mathrm{tn}=$ tidak nyata

Tabel 7. Jumlah akar lateral bibit pada berbagai media pembibitan

\begin{tabular}{lccc}
\hline \multirow{1}{*}{ Media Pembibitan } & \multicolumn{3}{c}{ Jumlah akar lateral } \\
\cline { 2 - 4 } & HSPT & 60 & 90 \\
& $20.80 \mathrm{ab}$ & 24.80 & HSPT \\
\hline Tanah $(\mathrm{T})$ & $12.20 \mathrm{ab}$ & 18.40 & 18.60 \\
T + Serbuk gergaji & $24.60 \mathrm{a}$ & 23.60 & 22.60 \\
T + Cocopeat & $11.40 \mathrm{~b}$ & 20.80 & 17.00 \\
T + Tongkol jagung & $15.60 \mathrm{ab}$ & 26.60 & 21.60 \\
T + Daun bambu & 12.42 & tn & tn \\
\hline BNJ 5\% & & &
\end{tabular}

Keterangan: Angka yang diikuti dengan huruf yang sama pada kolom yang sama menunjukkan berbeda tidak nyata menurut uji BNJ pada taraf nyata $5 \% . \mathrm{HSPT}=$ hari setelah pindah tanam. $\mathrm{tn}=$ tidak nyata.

Pada Tabel 8. tampak ada pengaruh nyata macam media pembibitan terhadap bobot segar dan bobot kering tajuk bibit umur 30 HSPT dan berpengaruh tidak nyata pada bibit umur 60 HSPT dan 90 HSPT. Macam media pembibitan yang digunakan berpengaruh nyata terhadap bobot segar dan bobot kering akar bibit selama 3 bulan periode pertumbuhan (Tabel 9). Bobot segar akar bibit pada media tanah-cocopeat berbeda tidak nyata dengan bibit pada media lainnya, kecuali dengan bibit pada media tanah yang berbeda tidak nyata dengan bibit pada media tanah-serbuk gergaji, tanah-hancuran tongkol jagung, dan tanah-seresah daun bambu saat bibit umur 90 HSPT. Sebagai manifestasi dari pertumbuhan akar bibit, maka diamati bobot kering akar bibit selama periode 3 bulan pertumbuhannya. Saat bibit berumur 90 HSPT, bobot kering akar pada media tanah-cocopeat berbeda tidak nyata dengan bibit pada media lainnya, kecuali dengan bibit pada media tanah yang berbeda tidak nyata dengan bibit pada media tanah-serbuk gergaji, tanah-hancuran tongkol jagung, dan tanah-seresah daun bambu.

Kualitas bibit yang baik dapat diidentifikasi melalui nilai rasio tajuk dan akar bibit. Nilai rasio tajuk-akar yang mendekati nilai satu menunjukkan bahwa pertumbuhan tajuk dan akar bibit yang seimbang. Tabel 10. menunjukkan bahwa pada bibit umur 30 HSPT, semua bibit pada macam media pembibitan memiliki rasio tajuk-akar lebih besar dari niali satu, kecuali media campuran tanah-serbuk gergaji. Sedangkan pada saat bibit berumur 60 HSPT, rasio tajuk-akar bibit pada media tanah-cocopeat, tanah-hancuran tongkol jagung, dan tanah- 
seresah daun bambu memilki rasio tajuk-akar yang mendekati nilai satu. Bibit pada macam media pembibitan memiliki nilai rasio tajuk-akar yang mendekati nilai satu saat bibit umur 90 HSPT, kecuali bibit pada media tanah yang masih memiliki nilai rasio tajuk-akar lebih dari nilai satu.

Tabel 8. Bobot segar dan bobot kering tajuk bibit pada berbagai media pembibitan

\begin{tabular}{lcccccc}
\hline \multirow{2}{*}{ Media Pembibitan } & \multicolumn{3}{c}{ Bobot segar $(\mathrm{g})$} & \multicolumn{3}{c}{ Berat kering $(\mathrm{g})$} \\
\cline { 2 - 7 } & 30 & 60 & 90 & 30 & 60 & 90 \\
& HSPT & HSPT & HSPT & HSPT & HSPT & HSPT \\
\hline Tanah (T) & $3.46 \mathrm{bc}$ & 21.89 & 30.35 & $0.66 \mathrm{~b}$ & 3.73 & 5.14 \\
T + Serbuk gergaji & $2.16 \mathrm{c}$ & 15.09 & 24.34 & $0.38 \mathrm{c}$ & 2.39 & 4.06 \\
T + Cocopeat & $4.12 \mathrm{~b}$ & 18.75 & 34.92 & $0.72 \mathrm{~b}$ & 3.28 & 5.78 \\
T + Tongkol jagung & $3.56 \mathrm{bc}$ & 19.78 & 34.06 & $0.65 \mathrm{~b}$ & 3.31 & 5.64 \\
T + Daun bambu & $6.42 \mathrm{a}$ & 21.47 & 30.00 & $1.21 \mathrm{a}$ & 3.76 & 5.23 \\
\hline BNJ 5\% & 1.52 & tn & tn & 0.27 & tn & tn
\end{tabular}

Keterangan: Angka yang diikuti dengan huruf yang sama pada kolom yang sama menunjukkan berbeda tidak nyata menurut uji BNJ pada taraf nyata $5 \%$. HSPT = hari setelah pindah tanam. $\mathrm{tn}=$ tidak nyata

Tabel 9. Bobot segar dan bobot kering akar bibit pada berbagai media pembibitan

\begin{tabular}{lcccccc}
\hline \multirow{2}{*}{ Media Pembibitan } & \multicolumn{3}{c}{ Bobot segar $(\mathrm{g})$} & \multicolumn{3}{c}{ Bobot kering $(\mathrm{g})$} \\
\cline { 2 - 7 } & HSPT & HSPT & HSPT & HSPT & HSPT & HSPT \\
\hline Tanah (T) & $2.64 \mathrm{~b}$ & $15.26 \mathrm{~b}$ & $28.23 \mathrm{~b}$ & $0.43 \mathrm{~b}$ & $2.50 \mathrm{bc}$ & $4.54 \mathrm{~b}$ \\
T + Serbuk gergaji & $3.27 \mathrm{~b}$ & $15.38 \mathrm{ab}$ & $36.59 \mathrm{ab}$ & $0.57 \mathrm{ab}$ & $2.14 \mathrm{c}$ & $5.37 \mathrm{ab}$ \\
T + Cocopeat & $4.97 \mathrm{a}$ & $22.14 \mathrm{ab}$ & $48.26 \mathrm{a}$ & $0.67 \mathrm{ab}$ & $3.85 \mathrm{ab}$ & $7.69 \mathrm{a}$ \\
T + Tongkol jagung & $3.06 \mathrm{~b}$ & $19.55 \mathrm{ab}$ & $38.47 \mathrm{ab}$ & $0.39 \mathrm{~b}$ & $3.37 \mathrm{abc}$ & $6.49 \mathrm{ab}$ \\
T + Daun bambu & $5.40 \mathrm{a}$ & $22.73 \mathrm{a}$ & $41.44 \mathrm{ab}$ & $0.86 \mathrm{a}$ & $4.12 \mathrm{a}$ & $6.92 \mathrm{ab}$ \\
\hline BNJ 5\% & 1.66 & 7.39 & 14.00 & 0.30 & 1.51 & 2.45 \\
\hline
\end{tabular}

Keterangan: Angka yang diikuti dengan huruf yang sama pada kolom yang sama menunjukkan berbeda tidak nyata menurut uji BNJ pada taraf nyata 5\%. HSPT = hari setelah pindah tanam

Tabel 10. Rasio tajuk akar bibit pada berbagai media pembibitan

\begin{tabular}{lccc}
\hline \multirow{2}{*}{ Media Pembibitan } & \multicolumn{3}{c}{ Rasio Tajuk-Akar } \\
\cline { 2 - 4 } & 30 SPT & 60 HSPT & 90 HSPT \\
\hline Tanah $(\mathrm{T})$ & 1.89 & 1.58 & 1.18 \\
T + Serbuk gergaji & 0.70 & 1.27 & 0.77 \\
T + Cocopeat & 1.15 & 0.90 & 0.81 \\
T + Tongkol jagung & 1.81 & 0.98 & 0.88 \\
T + Daun bambu & 1.42 & 0.93 & 0.76 \\
\hline
\end{tabular}

Tabel 11. menjelaskan laju pertumbuhan tajuk dan akar bibit dilihat dari peningkatan bobot segar dan bobot kering selama 3 bulan periode pertumbuhan bibit. Macam media pembibitan tampak berpengaruh tidak nyata terhadap laju pertumbuhan tajuk bibit, namun berpengaruh nyata terhadap laju pertumbuhan akar bibit. Bibit pada media tanah-cocopeat 
memiliki bobot segar dan bobot kering akar yang berbeda tidak nyata dengan bibit pada media lainnya, kecuali dengan bibit pada media tanah.

Tabel 11. Laju pertumbuhan tajuk dan akar bibit selama 3 bulan periode pertumbuhan pada macam media

\begin{tabular}{lcccc}
\hline \multirow{2}{*}{ Media } & \multicolumn{2}{c}{ Laju pertumbuhan tajuk } & \multicolumn{2}{c}{ Laju pertumbuhan akar } \\
\cline { 2 - 5 } & $\begin{array}{c}\text { Bobot segar } \\
(\mathrm{g})\end{array}$ & $\begin{array}{c}\text { Bobot kering } \\
(\mathrm{g})\end{array}$ & $\begin{array}{c}\text { Bobot segar } \\
(\mathrm{g})\end{array}$ & $\begin{array}{c}\text { Bobot kering } \\
(\mathrm{g})\end{array}$ \\
\hline Tanah $(\mathrm{T})$ & 13.44 & 2.24 & $12.79 \mathrm{ab}$ & $2.06 \mathrm{ab}$ \\
T + Serbuk gergaji & 11.08 & 1.84 & $16.66 \mathrm{~b}$ & $2.40 \mathrm{~b}$ \\
T + Cocopeat & 15.40 & 2.53 & $21.64 \mathrm{a}$ & $3.51 \mathrm{ab}$ \\
T + Tongkol jagung & 15.25 & 2.49 & $17.70 \mathrm{ab}$ & $3.05 \mathrm{ab}$ \\
T + Daun bambu & 11.79 & 2.01 & $18.01 \mathrm{ab}$ & $3.03 \mathrm{a}$ \\
\hline BNJ 5\% & tn & tn & 6.79 & 1.23 \\
\hline
\end{tabular}

Keterangan: angka yang diikuti dengan huruf yang sama pada kolom yang sama menunjukkan berbeda tidak nyata menurut uji BNJ pada taraf nyata $5 \%$. tn = tidak nyata. $\mathrm{HSPT}=$ hari setelah pindah tanam.

\section{Pembahasan}

Pada komponen tajuk bibit, terutama diameter batang, tampak bahwa media campuran tanah-cocopeat, tanah-hancuran tongkol jagung, dan tanah-seresah daun bambu berpengaruh paling baik dibandingkan dengan media tanah dan tanah-serbuk gergaji. Media campuran tanah-cocopeat memiliki kadar air yang paling tinggi dibandingkan kadar air media pembibitan lainnya (27.09\%). Meskipun media campuran tanah-cocopeat memiliki berat jenis yang paling rendah (1.66 g. $\left.\mathrm{ml}^{-1}\right)$, namun jika dilihat dari kadar air yang terikat cukup tinggi maka dapat dikatakan bahwa media ini memiliki porositas yang baik. Hal ini sejalan dengan pernyataan Hasriani et al. (2013), bahwa media sapih cocopeat memiliki kadar air dan daya simpan air masing-masing sebesar $119 \%$ dan $695.4 \%$ Media sapih cocopeat memiliki pori mikro yang mampu menghambat gerakan air lebih besar sehingga menyebabkan ketersediaan air lebih tinggi (Valentino, 2012).

Media campuran tanah-cocopeat juga memiliki nilai $\mathrm{C} / \mathrm{N}$ yang tergolong sangat rendah (4.56). Berdasarkan hal ini, dapat dikatakan bahwa kadar N-tersedia cukup tinggi pada media campuran tanah-cocopeat. Sari (2015) menyatakan bahwa peningkatan komposisi media tanam cocopeat-tanah-pasir (5:2:2) mampu meningkatkan jumlah daun per rumpun, volume akar, rasio tajuk dan umbi berat basah bawang merah, dan rasio tajuk umbi berat kering tertinggi.

Media campuran tanah-hancuran tongkol jagung memiliki sifat fisik dan sifat kimia yang mendukung pertumbuhan bibit kelor. Media ini memiliki kadar air yang lebih rendah jika dibandingkan dengan kadar air media pembibitan lainnya (16.10\%), sedangkan berat jenis media ini lebih tinggi dibandingkan media tanah-serbuk gergaji dan tanah-cocopeat (2.00 g. $\left.\mathrm{ml}^{-1}\right)$ dan porositasnya relatif lebih rendah. Nilai $\mathrm{C} / \mathrm{N}$ media tanah-hancuran tongkol jagung yang tergolong sangat rendah, sama halnya seperti nilai $\mathrm{C} / \mathrm{N}$ media campuran tanahcocopeat (4.90).

Media campuran tanah-seresah daun bambu memiliki Kapasitas Tukar Kation (KTK) yang tergolong sedang $\left(17.34 \mathrm{cmol} . \mathrm{kg}^{-1}\right)$. Kapasitas Tukar Kation media campuran tanahseresah daun bambu lebih baik dibandingkan KTK media pembibitan lainnya yang tergolong 
rendah dan hal ini juga mengindikasikan kemampuan media dalam menjerap dan mempertukarkan kation cukup tinggi. Selain itu, nilai C/N media ini tergolong rendah (10.36) yang berarti ketersediaan unsur $\mathrm{N}$ cukup tinggi dan mudah diabsorpsi akar tanaman. Wijayanti (2012) menyebutkan bahwa komposisi media tanam 100\% daun bambu meningkatkan tinggi tanaman tomat pada umur 2-5 MST, jumlah daun pada umur 2-4 MST, jumlah bunga pada umur 5 MST, 7 MST, 8 MST, dan meningkatkan jumlah tandan bunga pada umur 5 MST-11 MST.

Media campuran tanah-cocopeat, tanah-hancuran tongkol jagung, tanah-seresah daun bambu memiliki kadar P-tersedia yang tergolong tinggi (9.03 ppm, 8.54 ppm, dan 8.75 ppm) dan kadar K-tersedia yang tergolong sangat tinggi (52.12 ppm, 56.86 ppm, dan 51.48 ppm) sehingga pertumbuhan tajuk pada ketiga media ini paling baik dibandingkan dua media lainnya. Ketersediaan unsur $\mathrm{N}$ juga tinggi dan mudah diabsorpsi akar tanaman. Ketiga unsur ini sangat dibutuhkan tanaman pada fase vegetatif seperti pembentukan daun, batang dan akar.

Media tanah berpengaruh kurang baik terhadap pertumbuhan tajuk bibit. Hal dikarenakan media tanah memiliki sifat fisik dan kimia yang kurang mendukung pertumbuhan bibit. Media ini memiliki berat jenis yang lebih tinggi dari media pembibitan lainnya yaitu 2.07 g. $\mathrm{ml}^{-1}$ (porositas relatif lebih rendah) dan kadar air lebih tinggi dibandingkan media tanah-hancuran tongkol jagung dan tanah-seresah daun bambu (20.57). Porositas yang rendah pada media ini menyebabkan pemadatan yang kurang baik untuk pertumbuhan akar. Irawan dan Kafiar (2015) juga menyatakan bahwa tanah (Top soil) yang cenderung padat akan menyebabkan aerasi kurang baik sehingga akar bibit cempaka wasian tidak dapat berkembang secara maksimal. Pada media tanah hanya digunakan tanah tanpa ada penambahan bahan organik yang menyebabkan C-organik tergolong sangat rendah $(0.29 \%)$. Kondisi ini semakin diperparah oleh rendahnya KTK media (12.56 cmol. $\left.\mathrm{kg}^{-1}\right)$ dan ketersediaan unsur P tergolong sedang (5.5 ppm) meskipun K-tersedia tergolong sangat tinggi (48.32 ppm).

Kadar unsur $\mathrm{P}$ pada media campuran tanah-serbuk gergaji tergolong sangat tinggi (13.86 ppm), lebih tinggi dibandingkan media pembibitan lainnya. Selain itu, kadar unsur K juga tergolong sangat tinggi pada media ini (52.64 ppm). Meskipun demikian, pengaruh media campuran tanah-seruk gergaji kurang baik terhadap pertumbuhan tajuk bibit. Santoso et al. (2009) menyatakan bahwa ada pengaruh negatif senyawa kimia hasil dekomposisi awal dari bahan serbuk kayu yang menyebabkan cekaman "alelopati" pada pertumbuhan dan perkembangan bibit jarak pagar. Media campuran tanah-serbuk gergaji merupakan media campuran yang menyebabkan hambatan pertumbuhan dan perkembangan bibit. Tingkat porositas yang tinggi menyebabkan kurang eratnya daya pegang atau sentuhan antara akar dan media walaupun kadar air saat kapasitas lapang media tanah-serbuk gergaji-pupuk kandang paling tinggi. Porositas yang tinggi menyebabkan KTK media campuran tanahserbuk gergaji menjadi rendah.

Pada komponen akar bibit, terutama bobot berangkasan segar dan bobot berangkasan kering, media campuran tanah-cocopeat cenderung berpengaruh lebih baik dibandingkan media pembibitan lainnya, terutama terhadap parameter bobot segar dan bobot kering akar. Hal ini dikarenakan media ini memiliki porositas yang baik, kadar air dan kandungan unsur NPK yang tergolong tinggi. 
Bibit pada media tanah memiliki pertumbuhan akar yang cenderung kurang baik dibandingkan bibit pada media lainnya. Hal ini disebabkan sifat fisik media terutama porositas yang dapat dikatakan rendah pada media ini sehingga menyebabkan pemadatan, aerasi dan drainase media juga kurang baik.

Rasio tajuk-akar menentukan kualitas bibit tanaman. Kualitas bibit yang baik adalah bibit yang mempunyai pertumbuhan seimbang antara bagian atas dengan bagian akar tanaman (rasio tajuk-akar). Bibit yang memiliki nilai rasio tajuk-akar kurang dari nilai satu memiliki daya adaptasi yang lebih baik di lapangan dibandingkan bibit dengan rasio tajukakar lebih dari nilai satu. Bibit yang memiliki rasio tajuk-akar mendekati nilai satu yaitu bibit pada media campuran tanah-hancuran tongkol jagung (0.88), kemudian diikuti bibit pada media campuran tanah-cocopeat (0.81), tanah-serbuk gergaji (0.77), tanah-seresah daun bambu (0.76), dan media tanah dengan nilai rasio tajuk akar lebih dari nilai satu (1.18).

Pertumbuhan bibit yang baik sangat dipengaruhi oleh jenis media pembibitan yang digunakan. Media pembibitan yang baik memiliki kondisi fisik dan kimia yang optimal. Jadi, media pembibitan campuran tanah-cocopeat, campuran tanah-hancuran tongkol jagung, dan campuran tanah-seresah daun bambu berpengaruh lebih baik terhadap pertumbuhan bibit dibandingkan media tanah dan campuran tanah-serbuk gergaji.

\section{KESIMPULAN}

Macam media pembibitan organik berpengaruh nyata terhadap pertumbuhan bibit kelor asal biji selama 3 bulan periode pertumbuhan. Media campuran tanah-cocopeat, tanahhancuran tongkol jagung, dan tanah-seresah daun bambu merupakan media terbaik dan lebih cocok bagi pembibitan kelor dibandingkan media tanah dan campuran tanah-serbuk gergaji

Media pembibitan tanaman kelor dapat menggunakan limbah tanaman sebagai tambahan bahan organik dalam media, terutama sisa serbuk sabut kelapa (cocopeat), tongkol jagung, dan seresah daun bambu. Bibit kelor yang ditanam pada polybag ukuran 20x26 cm sebaiknya dipindah tanam ke lapangan saat bibit berumur 2 bulan (60 HSPT). Selain itu juga perlu dilakukan penelitian lebih lanjut untuk mengetahui perbandingan yang baik digunakan untuk pencampuran masing-masing media dan juga untuk mengetahui ukuran polybag yang cocok untuk pembibitan kelor kaitannya dengan volume media.

\section{DAFTAR PUSTAKA}

[BPT] Balai Penelitian Tanah. 2005. Petunjuk Teknis Analisis Kimia Tanah, Tanaman, Air, dan Pupuk. Balai Penelitian Tanah. Bogor.

[BMKG] Badan Meteorologi, Klimatologi dan Geofisika. 2011. Analisis Hujan Bulan Januari 2011 dan Prakiraan Hujan Bulan Maret, April, dan Mei 2011 Provinsi Banten dan DKI Jakarta. Stasiun Klimatologi Pondok Betung. Tangerang.

[BMKG] Badan Meteorologi, Klimatologi dan Geofisika. 2017. Data Iklim Bulan Januari, Februari, Maret, April Tahun 2017 di Lombok Barat dan Mataram. Stasiun Klimatologi Kelas I Lombok Barat. NTB.

Dalimoenthe, S.L. 2013. Pengaruh media tanam organik terhadap pertumbuhan dan perakaran pada fase awal benih teh di pembibitan. Jurnal Penelitian Teh dan Kina. 16 (1) : 1-11.

Hasriani, D.K. Kalsim, A. Sukendro. 2013. http://dedikalsim.wordpress.com. [25 November 2016]. 
Irawan, A., Y. Kafiar . 2015. Pemanfaatan cocopeat dan arang sekam padi sebagai media tanam bibit cempaka wasian (Elmerrilia ovalis). Pros Sem Nas Masy Biodi Indo. 1(2): 805-808.

Krisnadi, A.D. 2015. http://kelorina.com/blog /ebook-kelor-super-nutrisi/. [17 November 2016].

[BPTP NTB] Balai Pengkajian Teknologi Pertanian NTB. 2017. Laporan Hasil Pengujian Sampel Media Pembibitan. Balai Pengkajian Teknologi Pertanian NTB. NTB.

Nawi, A.B.M. 2015. Biodiesel production from moringa oleifera seeds oil using mgo as a catalyst. Tesis. Universitas Malaysia Pahang. Malaysia.

[PPR/RL] Pilot Proyek Restorasi/Rehabilitasi Lahan. 2013. Modul Pelatihan Persemaian. Integrated Citarum Water Resources Management Investment Program (ICWRMIP) And Citarum Watershed Management And Biodiversity Conservation (CWMBC).

Santoso, B.B. 2009. Karakterisasi Morfo-ekotipe dan Kajian Beberapa Aspek Agronomi Jarak Pagar (Jatropha curcas L.) di Nusa Tenggara Barat. Disertasi. Institut Pertanian Bogor. Bogor. Indonesia.

Santoso, B.B., Hariyadi., Purwoko B. S. 2009. Pertumbuhan bibit jarak pagar asal biji dan stek pada berbagai macam media pembibitan. Crop Agro. 2 (2) : 1-11

Sari, D.R. 2015. Aplikasi konsentrasi paklobutrazol pada beberapa komposisi media tanam berbahan cocopeat terhadap pertumbuhan dan hasil bawang merah (Allium ascalonicum L). Skripsi. Program Studi Agroekoteknologi Fakultas Pertanian Universitas Jember. Jember. Indonesia.

Valentino, N. 2012. Pengaruh pengaturan kombinasi media terhadap pertumbuhan anakan cabutan tumih (Combretocarpus rotundatus). Skripsi. Institut Pertanian Bogor. Bogor. Indonesia.

Wijayanti, E. 2012. Pengaruh Komposisi Media Tanam terhadap Pertumbuhan dan Produksi Dua Varietas Tomat (Lycopersicon Esculentum Mill) secara Hidroponik. Skripsi. Departemen Agronomi Dan Hortikultura Fakultas Pertanian Institut Pertanian Bogor. Bogor. Indonesia. 